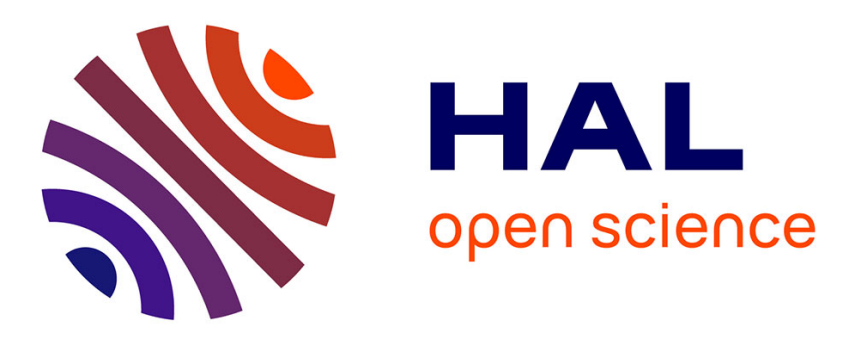

\title{
Executives' perspectives of the changing role of the sales profession: views from France, the United States, and Mexico
}

\author{
John Tanner, Christophe Fournier, Jorge Wise, Sandrine Hollet-Haudebert, \\ Fanny-Juliet Poujol
}

\section{To cite this version:}

John Tanner, Christophe Fournier, Jorge Wise, Sandrine Hollet-Haudebert, Fanny-Juliet Poujol. Executives' perspectives of the changing role of the sales profession: views from France, the United States, and Mexico. Journal of Business and Industrial Marketing, 2008, 23 (3), pp.193 - 202. 10.1108/08858620810858454. hal-01765014

\section{HAL Id: hal-01765014 \\ https://hal.science/hal-01765014}

Submitted on 26 Jan 2021

HAL is a multi-disciplinary open access archive for the deposit and dissemination of scientific research documents, whether they are published or not. The documents may come from teaching and research institutions in France or abroad, or from public or private research centers.
L'archive ouverte pluridisciplinaire HAL, est destinée au dépôt et à la diffusion de documents scientifiques de niveau recherche, publiés ou non, émanant des établissements d'enseignement et de recherche français ou étrangers, des laboratoires publics ou privés. 


\title{
Executives' perspectives of the changing role of the sales profession: views from France, the United States, and Mexico
}

\author{
fohn F. Tanner fr \\ Hankamer School of Business, Baylor University, Waco, Texas, USA \\ Christophe Fournier \\ Research Center in Management of Organizations (CR2M), Université Montpellier 2, Institut Universitaire de Technologie, \\ Techniques de Commercialisation, Montpellier, France \\ forge A. Wise \\ International Business Department, Instituto Tecnológico y de Estudios Superiores de Monterrey, Monterrey, Mexico \\ Sandrine Hollet \\ Institute of Research in Management (IRG) - University of Paris 12, Institut Universitaire de Technologie, \\ Techniques de Commercialisation, Créteil, France, and
}

Fuliet Poujol

INSEEC Business School, Paris, France

\begin{abstract}
Purpose - This paper aims to present perceptions of sales executives from three countries regarding expectations for the future of the sales profession and sales position.

Design/methodology/approach - Results of a thematic interpretation of in-depth interviews are presented, using several agenda-setting articles as a foundation.

Findings - Executives struggle with how salespeople should add value, especially in today's multi-channel environment. Greater professionalization is needed in countries where the state of the profession is less developed. Emergent strategy is practiced but not universally. Sales executives generally believe that little incremental value in technology can be gained, though it is apparent that technology is not being fully utilized. Other findings are also discussed.

Research limitations/implications - Researchers should consider classifying sales research by sales strategy rather than industry or country unless those aspects are factors being studied; further, questions such as how do salespeople create value and when is human intervention in the sales process required are offered.

Practical implications - Executives should re-examine sales technology, particularly in managing and transferring knowledge. Emergent strategy requires processes for identifying and transferring effective adaptation. Sales organizations must develop, at the salesperson level, greater business acumen, to be gained through training, experience or selection.

Originality/value - This study identifies issues and factors that will influence sales practice and should influence sales research into the future. Particularly, the study is the first to highlight the use of emergent strategy, as well as the issue of identifying and creating value.
\end{abstract}

Keywords Sales management, Sales training, France, United States of America, Mexico, Perception

Paper type Research paper

An executive summary for managers and executive readers can be found at the end of this article.

In the last decade the nature of the sales profession has changed tremendously (Ingram, 2004). For example, Leigh and Marshall (2001) wrote: "the sales function is undergoing an unparalleled metamorphosis, driven by the plethora of changing conditions..." (p. 92). Shapiro et al. (1994) foreshadowed this decade of change, suggesting that the "world of selling must accommodate a dramatically changed world of buying" (p. 1). Since penning that phrase, the world of selling may have changed even more. Globalization, technology, increased emphasis on customer/vendor relationships, the growth of team selling, and other factors have significantly altered how salespeople work (Ingram, 2004). 
Ingram et al. (2002) reported: "The sales function is in the midst of a renaissance - a genuine rebirth and revival" (p. 559). In order to understand how the responsibility of the salesperson is changing, Leigh and Marshall (2001) stated: "Capturing and leveraging the professional intellect of leading sales executives is a major research issue" (p. 91). This thematic study explores that professional intellect through the results of over one hundred depth interviews with sales executives in Europe, the US and Mexico regarding what the future holds for the sales profession.

\section{The future of selling}

To guide the thematic study of the professional intellect, several research agenda articles served as a foundation. Beginning at the turn of the millennium, academicians have considered the rapid changes in selling and the implications for research. The first effort was the AMA Faculty Consortium where 94 academicians, 12 executives, two consultants and two representatives of the Direct Selling Education Foundation collaborated to identify a list of some 66 research priorities (Marshall and Michaels, 2001). At the same time, Leigh and Marshall's (2001) development of research priorities followed by Ingram et al.'s (2002) joint research agenda, offered researchers a slightly different reflection on the future of selling. Ingram et al. (2002) termed theirs a "joint agenda," meaning that it would require the joint efforts of academicians and practitioners. The joint agenda concentrates on "three broad interrelated areas that will be most crucial for future sales force and organizational success" (p. 559). These areas are developing sales strategies; providing sales force leadership, and using technology effectively. Similarly, Ingram's (2004) look into the future also focused on three topics: complexity, collaboration, and accountability.

Consistent across agenda articles is the question of the role of the selling function and the salesperson. Ingram et al.(2002) address the role in the context of sales strategies while Leigh and Marshall (2001) ask how those roles change when a company adopts a customer centric or market oriented strategy and culture. As they note, "a key challenge is to establish the value of the marketing function, and explicitly the selling function, in a customer-driven firm" (p. 85). Robertson et al. (2006) identify the role of the sales force as the most important research issue in financial services when they raise the question, "what is the domain of the sales force?" (p. 296). Clearly, understanding the changing role of the salesperson is a critical theme throughout these research priorities.

Another relevant theme mentioned in each article is technology; technology pervades the discussion of all practices. For example, how technology can aid in segmentation is one issue (Robertson et al., 2006). Similar questions permeate the priorities; yet, Leigh and Marshall note that "descriptive research concerning how firms are to realize the benefits of IT in the environment is limited" (p. 88).

The third theme is people, a theme representing nine of the top ten research priorities identified by Robertson et al. (2006). Like IT, selection and development of salespeople is also a best practice and is treated separately by Leigh and Marshall (2001). Ingram (2004), however, views the issue from the process perspective, discussing the importance of collaboration. The theme, though, is pervasive as they note the different activities, behaviors, and mindsets needed to accomplish such dramatic changes as a move from transactional selling to customer-centricity.

Ingram et al. (2002) and Robertson et al. (2006), however, also focus on leadership, consistent with their more macrolevel approach. While Ingram et al. (2002) recognize the importance of salesperson selection and development, their focus is on the selection and development of sales managers, along with the importance of developing the right sales manager-salesperson relationships whereas Robertson et al. (2006) also consider issues surrounding communicating the right vision and creating the right culture. The end result should be better selection and development process of salespeople as well, for as Ingram et al. (2002) recognize, "emerging models of sales leadership and extensive sales supervision research indicate that individual sales managers play an important role in shaping salesperson attitudes and behaviors" (p. 563).

This study explores these themes qualitatively by examining the professional intellect (Leigh and Marshall, 2001). The purpose is not so much to generate yet another research agenda as that has been done and done well; rather, our objective is to qualitatively explore the state of current practice and expectations for future practice along the themes developed elsewhere.

Since we are concerned with the state of sales management, now and into the future, we consider responses from executives in three countries that have developed at different rates: the US, France and Mexico. While any number of countries could have been chosen, these were selected for two primary reasons. The first reason is that selling is a more accepted profession in the US than in either France (Darmon, 1997; Barth and Biardeau, 2002) or Mexico and should be more advanced as a consequence; such differences may provide interesting insight into the changing nature of the sales profession. The second reason is the nature of the economies of France and Mexico, dependent as they are on selling internationally. Even though sellers are found everywhere, both France and Mexico have a respectable level of selling activity among them and particularly with the US. The choice was not driven by a desire to study cultural differences; one could argue that these countries are similar in many respects. Rather, the concern is the maturity of the sales profession (Darmon, 1997) and what that might mean to how we move into the future. In the next section, we discuss a depth-interview study of sales executives in three countries.

\section{The study}

A qualitative study utilizing depth interviews was undertaken in order to develop themes that are important to sales executives. While this design cannot yield conclusive evidence (e.g. Strauss and Corbin, 1990), the purpose is to develop insight into the professional intellect of the sales executive with regard to issues and factors that press upon that intellect. To that end, an interviewer's guide was developed that consisted primarily of the following questions:

1 What do you see as the future of professional selling - the

sales job, the sales function, the sales career? How do you see the role of the salesperson changing over the next five to ten years?

2 What impact is technology having on the sales profession? 


\section{What will the impact of these trends (identified in}

response to the first two questions) be on selection and training? What will the impact of technology be on selection and training?

These open-ended questions (Fontana and Frey, 1998) were asked in the local language by native speakers in three countries (cf. Ji et al., 2004), the US, Mexico, and France, following a brief discussion of the number of salespeople employed, the nature of the products sold, and the nature of the market in which the organization operated. The latter discussion included intensity of competition, number and size of customers, and similar factors that might influence the nature of the market. All questions were translated using the back-translation process (Craig and Douglas, 2000) that offers proper equivalence across the three languages.

Our interpretations are drawn from the text of directive interviews (e.g. Bernthal et al., 2005), a method appropriate when seeking to identify phenomena that are difficult to convey with survey methodology (e.g. Trocchia, 2004). At the beginning of analysis, the data were "chunked," a process similar to the initial phases of laddering (Deeter-Schmelz et al., 2002; Gengler and Reynolds, 1995). This process begins with breaking conversational data into meaningful phrases. A meaningful phrase is one that encompasses a single concept. Jokes, sidebar comments, and the like were deleted from consideration. The current analysis method, thematic interpretation, was used to identify themes (Rapert et al., 1998). A theme represents a topic discussed both frequently and in depth by several participants and supported by several related sub-themes (cf. O'Sullivan et al., 2000).

While taking a more phenomenological than grounded theoretical approach (e.g. Goulding, 2005) in that this is not theory-driven or theory-deriving research, the method employed is thematic interpretation in an effort to develop an understanding of the professional intellect. Further, sampling was purposively broad. Again, this being a qualitative study attempting to identify and explore issues relevant in the sales profession, the sample frame intentionally included executives from disparate sales organizations and industries. The percentages of respondents or phrases or concepts could be reported, and tests could be run to examine statistically for differences among the French, the American and the Mexican samples. Such tests would be inappropriate due to the purposive nature of the sample, the goals of the study, and the nature of qualitative research.

The sample consisted of 54 sales executives across the US, 31 in France and 20 in Mexico. In each case, an initial contact was made to identify the chief sales officer of the firm. Sales forces ranged in size from four salespeople to over 1,000. By intent, the non-probability sample included independent manufacturers' representative firms, capital equipment sales, financial services (business to consumer, as well as institutional), pharmaceutical sales, information technology consulting, supply sales, maintenance repair and operation (MRO) sales, among others.

The time taken for the interviews was between 45 minutes and one hour and a half. The heterogeneous sample used gives certain level of representativeness of the sales force while the selection of the chief sales officer provides comparability between-countries (Reynolds et al., 2003).

\section{Findings and discussion}

Given that three themes guided the development of the questions used in the study, there is the potential that this method would result in overly positive confirmation of those themes. One purpose of a general opening question is that it allows the respondent to provide some direction for the interview, a direction that may not confirm any a priori themes. Further, an effort was made to identify counter-statements; that is, statements that either run counter to the theme or to the prevailing sentiment of the sales executives interviewed. Often, such counter-themes can prove useful in setting the theme into context, in identifying countervailing forces influencing perspectives, and to identify alternative perspectives worthy of additional consideration. We organize the discussion by theme, first discussing those supporting comments and sub-themes, then identifying the counter-statements and counter-themes.

Another challenge with the study is the imbalance in samples across the countries. A quantitative study can adjust for such an imbalance; the possibility that thematic development could be overwhelmed by the size of the American sample was addressed here by developing themes within each country sample, then comparing across the three samples.

\section{Changing role of the salesperson}

Discussion concerning the role of the salesperson often developed from the opening question that concerned the future of the profession.

\section{Future opportunity}

An interesting common first response to the question concerning the future of selling was that personal selling is not going to go away and the future "looks bright." There was almost defensive response to the question. Indeed, "face-to-face contact will never be replaced" mentioned a software sales manager. From a grocery wholesaler came this exclamation, "sales opportunities are going to be good!" A similar response was offered by a contract manufacturer's representative, "there are going to be some excellent opportunities." "The market is changing continuously" added an international sales executive in Latin America. These four executives and others, however, quickly went on to note that some opportunities will disappear as the market is changing rapidly. The consensus, though, is that face-to-face contact will continue, and perhaps prevail in developing customer relationships despite the expected constant change.

There were several executives who believed that the growing diversification of what is sold made the role of the salesperson more important. Similar to Ingram's (2004) discussion of complexity, one French executive in financial services declared, "15 years ago, we had 30 products to sell; now we have 250!" and went on to add that the salesperson is more important now. Another, in the automotive industry, reported that "sales reps now must not only sell cars, but also accessories, credit, insurance, or maintenance contracts." As a result, the executive added that new skills were needed because the importance of each salesperson increased.

The optimism regarding the crucial role of the seller was not universally shared by all French and Mexican counterparts. For example, one textiles sales executive believes that centralization of buying and selling will increase, decreasing the size or replacing the field sales 
force. The centralization theme was repeated by a food sales executive, who went on to state that the job will become less interesting and pay less. Similarly, multi-channel approaches involving the internet and other forms of marketing may yield different, and in some cases, reduced roles for salespeople, according to several executives.

\section{Career professionalization}

Despite contradictory viewpoints regarding the importance of selling, sales career professionalization is an imminent issue in every country, but it appears that greater progress has been made in the US. Many Mexican executives, for example, concluded that professional development of the sales force is a must. Thus, sellers should be more than the "everyday nice guy," as one Mexican executive put it, they used to be. Now, it is necessary to "know clients in advance and have a very good understanding of their own company," as one steel executive noted. The professional selling process requires sellers informed not only on the product or the client, but also on the industry and the environment. Further, there was agreement across countries that the integration into the sales position of one who plans, one who produces and one who sells will prevail, especially among those operating across international boundaries.

\section{A time of change}

Change in general

Change was raised by many participants independent of and

prior to any questions regarding change; nearly all

participants reported a significant rate of deep and broad

change in their industry. Depth refers to the degree of change

while breadth refers to the areas affected by change (Kelly, 1988); thus, deep change means that when things change, they change greatly. Broad changes affect many people and organizations in the industry and markets. As an international industrial sales manager (Mexico) noted, "sales are more complex everyday due to the constant of change." Hence, sales executives are saying that they are facing both deep and broad changes.

\section{Change in technology}

Most interviewees consider both deep and broad change to be due to technology. Interestingly, many executives believe that most of the technological revolution is complete. Technology has enabled a multi-channel go-to-market strategy that is less dependent upon salespeople. Multi-channel go-to-market strategy means that the same customer (or groups of customers) can interact (buy, pay, check order status, complain) through any number of channels such as field salespeople, call centers, online resources, and so forth. Multichannel retailers, for example, are those with some combination of brick-and mortar stores, catalogs, websites and other retailing methods (Tang and Xiaolin, 2001). In many instances, customer responsibility has fragmented, with the field salesperson having only a part of the responsibility for the relationship. Prospecting and post-sale service, for example, may be handled by other people or through technology in the multi-channel environment. One problem for the company and the different parts of the sales team is to have a "single unified view of the customer" (Payne and Frow, 2004).

Executives raise questions, therefore, about issues such as the development of trust and real relationships when so many channels are involved - do either trust or relationships really develop or is that simply "feel-good management," as expressed by one American executive. These results suggest that the role of the salesperson in a today's high-technology environment should be considered an important area of study.

\section{Change due to globalization}

Depending on the nature of the sales organization, globalization is another area of change. In many instances, the market served is (or was) local or regional (which could include trans-Europe) and there is an increasing concern about foreign (non-European) competitors. However, few executives in the US were concerned about globalization of their sales force while numerous Mexicans and French executives were concerned about the internationalization effects on their sales force. While in the US, one furniture manufacturing executive questioned whether his company could survive as a manufacturing company given the increased competition from China (as it turns out, the company did not survive). He noted that other companies were becoming distributors, and their salespeople had to adjust to the transition of manufacturing in the US at a company-owned plant to a contracted plant in China, with implications for customer service, product knowledge, and similar issues. Although the previous may be a function of several reasons such as industry type or location, the theme seemed more common among French and Mexican executives.

Conversely, the same disadvantage mentioned by US executives was mentioned as an advantage by a Mexican export manager: "it is easier today to enter new international markets." Similarly a package exec with sales in North America asserted "we live in a global economy, thus sellers should know what is happening in the global market."

Centralization of buying and consolidation (through mergers and acquisitions) is leading to increased globalization among buyers. One French manufacturer who sells to retailers noted that "the manufacturer's sales structure will follow the buying structure of the customer. If they are more global, we must adapt." Another French executive expected his key account managers to see increasing responsibility to negotiate for all of the customers' European locations, "and maybe for the world." This perspective seemed decidedly more European than American, either among US or Mexican executives.

\section{Emergent strategy}

Business schools have, for decades, taught the design approach for strategy (Mintzberg, 1994). The design approach, epitomized by the Harvard case method, suggests that strategy is separate from implementation. One theme, though, that could be identified among some of the responses is that the emergent strategy process (Mintzberg, 1994) is more descriptive of how sales executives create strategy. Similar to Moorman and Miner's (1998) conceptualization of product innovation as a result of improvisation, emergent strategy can be defined simply as trial and error, though others have seen it as the integration of implementation and strategy (Sashittal and Jassawalla, 2001).

For example, a security software sales executive said, "I'm a big testing guy, so I sent a guy to Minneapolis with a bunch of leads to see if he could close them." Entering a new market and testing its viability is an example of emergent strategy. Presumably, "if he could close them," then the company 
would shift resources to that new market. Some might argue that we are simply confusing tactics with strategy; however, the choice of new markets is considered strategic (Schill and McArthur, 1992). The issue, though, may be best resolved by exploring in future research whether emergent strategy is more descriptive of how strategy is actually accomplished.

As an executive from a motor coach company said, "our company is lucky because we are quicker and faster (at improvising and adapting) than anyone else out there, and that is a huge advantage." This statement reflects a highly adaptive and flexible company that can make use of emergent strategy, a point he emphasized saying, "our salespeople are important because they are usually the first to drive how we should change." Emergent strategy themes were more obvious among American responses although also noticed by some Mexicans. Interestingly, the issue of salespeople participating in strategy development within an emergent context first appeared in French research, not American research, when Bergadaà and Julien (1993) noted that salespeople will be part of the creation of company strategy. Support for this statement among French executives, however, never appeared in our interviews.

\section{Value creation}

More common to the three samples was the issue of value creation. Wotruba (1991) argued more than a decade ago that sales had evolved to the point where salespeople are now "value creators," professionals whose primary responsibility is creating value for both customer and company. Honeycutt et al. (2003) echoed this sentiment, which is precisely the case observed on both continents. Recall that earlier we identified a theme that there was agreement across countries that the integration into the sales position of one who plans, one who produces and one who sells will prevail. As salespeople take on additional responsibility back up the supply chain for planning and producing, value should be added.

One US office equipment manufacturer executive said that salespeople have to add value to the process or the buyer will buy from the Internet or other cheap sources, echoing a comment made by many. On the same topic, a Mexican executive from an insurance company claimed "buyers will demand more from the product while sellers must add value to the selling process." Margins are declining, and for companies to be able to afford salespeople, salespeople must create value to clients and to companies alike. The issue is not one of simply efficiency; i.e. selling more with the same resource. The issue is how to justify premium prices that reflect the cost of a professional sales force.

One French executive said that the question should be, "what is the contribution of each person to the company?" Thus, from the executives' perspective, the major element in the question of the salesperson's strategic role is "how a salesperson adds value," relative to other channels. Further, it is evident from executives' comments that they are expecting salespeople to determine how to add value in an emergent strategy way, which suggests far less centralization and more individualism than the earlier comments concerning globalization seem to allow.

Adding value is not simply to sell more, though one could certainly take that perspective from the office equipment executive's response of selling more to earn the same. Selling more does not necessarily justify premium prices that allow for paying a salesperson. Adding value means augmenting the product or service such that the buyer is willing to pay more because greater benefit is received. Recall the French executive's comment about the growing importance of salespeople because the complexity of products and add-ons was being increased. Whether due to growing technological complexity or the augmentation of the product through increased services, there was greater recognition among French and Mexican executives that salespeople are adding greater value to the selling process.

Note, however, the tension that can be identified: a diminishing role for salespeople given reliance on alternative channels mentioned earlier versus this increased reliance on salespeople to develop emergent strategy. As the role of salespeople diminishes, the opportunity and ability to develop strategy may also diminish, leading to a spiraling decline for the profession at the most dire, or at the least, a loss of organizational competitiveness. This tension seems to be a particularly rich area for research (see below) - for example, does technology that enhances management's ability to track salesperson performance result in less strategic development (or field-level adaptation)?

In sum, the theme of a changing role for the sales professional was clearly expressed by most sales officers. While sales executives foresee the continuance of professional selling, they indeed do anticipate the notion that the role of the salesperson is changing. Specifically, they recognize that salespeople develop emergent strategy "on the fly," as one executive says, and that professional salespeople's role will depend on how they add value.

\section{An alternative perspective}

While there was one American comment suggesting the demise of salespeople, several French and Mexican executives also believe that salespeople will decline in importance. Similar to the margin and competition pressures mentioned earlier, one American sales executive was convinced that field selling may disappear. As he says, "the internet has commoditized many businesses to the point that what we knew as salespeople will depart from this earth." Dramatic as that is, follow-up questions failed to distinguish any scope to that statement.

However, several French and Mexican executives noted that other channels will increase in importance to the detriment of salespeople. In that multi-channel environment, these executives see salespeople serving decision support roles rather than persuaders. A decision support person would be a resident expert, capable of answering questions and using soft sell methods such as suggestive selling. Among Americans, the view was more that if salespeople cannot add value, then they will devolve to decision support roles. However, the process of adding value could be a function of industry, product technology and change, and buying habits rather than an overall direction of the profession. This "American" view had its French and Mexican supporters as well; as one French insurance executive said, "I think that the call centers and Internet network will be dedicated to administrative tasks, or low added value, but the human interface will still be important."

\section{The impact of technology}

Technology is, to some extent, a great unknown, in spite of assertions by some executives that the technology revolution is over. For some sales executives, technology is about finding 
tools that enable their salespeople to do what they have always done but more efficiently. For others, the nature of technology is to fundamentally change the way their organization interacts with customers. For example, one French executive in financial services believes that technology is an important way to increase the productivity of the sales force, while another (in insurance) felt that the Internet could serve as a " $24 / 7$ " salesperson, selling around the clock seven days a week. Similarly, a Mexican executive considers that state-of-the-art technology as part of the everyday selling process helping to differentiate products in competitive markets.

A US food industry executive lamented the increase in information that is now available. Too much information yielded too much planning and not enough calls - in his opinion, one responsibility of management was to sift through the reams of information now available in order to put out to the field what was really needed. This comment, though, reflects a fairly common perspective: technology as information support tools. Despite the differences in opinions regarding technology among respondents, most French executives noted that the biggest benefit of technology was how it could capture and create opportunities to share information, a sentiment shared by both US and Mexican executives.

A French financial services executive believed that technology increased control over behavior rather than output, as behavior can now be tracked more easily. Other executives believed that access to information technology created more autonomous salespeople, as they had greater opportunity to create value with more information. Clearly, these executives are referring to different uses of technology, but the issue of autonomy is one that needs greater consideration, particularly as it relates to adaptation and emergent strategy.

Technology also provides more information to buyers. Online auctions, web data sources, and other technical influences have increased buyers' knowledge used to negotiate and to create greater competition (Carbone, 2005). Channel competition, long ago a challenge for academic research (Ingene and Parry, 1995), appears to be even stronger and more important to understand, in part because some executives say that the technology revolution will continue to alter the selling process.

\section{Selection and development of salespeople}

US executives mentioned, in this study, a growing trend to train salespeople in skills that are not related only to selling. One company recently provided speed reading lessons for the sales force while another brought in a voice coach in order to develop "rounder tones and more modulated voices." These types of training sessions could be due in part to the lack of development of any new sales models since the advent of SPIN in the early 1980s (e.g. Rackham, 1988). As another sales executive said, "the sales training packages are all alike and we've all been through them. Our salespeople actually asked for the speed reading course, as they spend a lot of their time reading and felt that this would increase their personal productivity." This comment was echoed by a US high-tech sales executive who reported the need to know something that will differentiate his salespeople who know how to sell and enable them to add value as he justified a decision to teach financial skills.
Conversely, another exec said he wanted people who had financial skills, and that experience was needed in order to understand financial statements and their impact on decisions. In his opinion, negotiation skills were needed, while financial skills were necessary to get hired. To help his salespeople understand how customers view competition when negotiating, he acquires competitive products for salespeople to study. From this study, they are able to identify strengths and weaknesses from the customer's perspective, resulting in more effective negotiating.

While some differences may have been due to industry differences, the overriding theme was to learn how to sell the way the customer wanted to buy. The French were much more concerned about selling skills, especially when selling to consumers. In one company, this meant improving phone selling skills; for another, negotiation skills. Among the French there was a greater emphasis on the need to learn basic selling methods, a need which also was found among the Mexican executives.

Further, there seemed more emphasis in France and Mexico on selection of salespeople as an area of concern. In France, executives report that selling is viewed less positively as a career choice confirming Darmon's (1997) earlier conclusion. As a result, the pool of potential candidates is not as desirable as some executives would like. Similarly, Mexican executives expressed their concern about the need to hire talented sellers. Executives in both countries were concerned that it may become even more difficult to find good people if the job became more mundane.

In sum, the future of selling will be marked by identifiable changes on several fronts. As summarized in Table I, many themes were identified from the empirical evidence. For example, there is a tension between using technology to enable adaptation and using technology to enforce standardization. Yet, other market-making technologies and activities (Kambil and Van Heck, 2002) are also changing the way buyers want to buy, which perforce changes how salespeople sell and the relative importance of their position.

\section{Managerial implications}

We have drawn inferences for managerial implications based on practices mentioned by managers or potential implications of their perceptions of the future. Discussion of managerial implications is necessarily limited in scope due to the nature of this study.

With that caveat, however, a number of implications can be drawn. For example, one theme is that salespeople may become multi-channel captains, at least in terms of how the company is presented to their clients. If that is the case, salespeople will need access to multi-channel tracking technology.

Managers often discussed the need for more business acumen among salespeople, which suggests a need for training and selection processes that are likely to result in such a sales force. One reason for greater business knowledge and ability is so that salespeople can deliver greater value; another is so that they can more effectively engage in emergent strategy. Yet, in France and Mexico, convincing this type of person to enter sales may be difficult due to the poor image of the profession.

If salespeople are indeed engaging in emergent strategy, processes for capturing successful and failing adaptation are 
Table I Themes identified, with sample research questions and managerial implications

\begin{tabular}{lll}
\hline Themes & Sample research questions & Sample managerial implications
\end{tabular}

Changing role of the salesperson

Change affecting the sales profession is both What are the causes of change that will have the broad and deep, and likely to continue into greatest impact on sales? the foreseeable future

More complex product offerings require salespeople - salespeople's value increases due to increased complexity in the market

What factors create complexity?

Career professionalization

Emphasis on value increases need for more professional salespeople who also understand broader picture

\section{A time of change}

Salespeople will be multi-channel captains, responsible for managing the account (less French support)

Globalization affects domestic and international markets

Globalization is an opportunity to sell overseas (more Mexican support)

\section{Emergent strategy}

Strategic planning will become more emergent, led by salespeople or sales management (more US support)

\section{Value creation}

Salespeople must add value, and it is up to What tasks contribute value? the salespeople to determine how

\section{The impact of technology}

Technology shortens decision cycles and access to information, making salespeople more productive (more Mexican support) Technology will make too much information available; thus a key executive role is determining what information is needed

What role does technology play in aiding salespeople to work smarter? How does technology add to collaboration?

What is the impact of globalization on sales positions?

What factors lead to more successful global selling?

What is the role of sales in developing strategy?
Understand market variables influencing choices of go-to-market strategy Prepare salespeople to develop agility capabilities in order to respond well to change

Requires methods, perhaps using technology, to manage the complexity of knowledge required to sell wide ranges of products

More emphasis on general business knowledge in training and development

Develop the culture to give salespeople a large view of their work

Multi-channel tracking technology is required Must build a system of motivation and compensation which considers all the actors of the channel and which avoids negative side-effects

Create culture oriented towards other countries and consumers to sell smarter? What data are useful for the manager and for the salesperson?

Technology will replace salespeople in some When is human intervention important? industries

Selection and development of salespeople Salespeople must become business people - What are these domains for additional training? leading to training in non-selling areas

Sales training must focus on selling skills (more French and Mexican support)

Finding effective salespeople is becoming more difficult (more French and Mexican support)
What are the skills required in a multi-channel environment for each member of the sales team?

What factors can predict sales success?
Identify, model, and disseminate value-producing activities. Develop a core competency in selling

Re-examine sales technology to integrate with existing systems and procedures

Creation of knowledge management systems and algorithms will be required

Determine and develop appropriate levels of access to information

Determine the degree to which customers will manage the relationship through self-service; develop rules for elevating to appropriate level of personal interaction

Develop appropriate mechanisms for human intervention at the right cost to serve levels

Assessment of sales skills and knowledge gaps must reflect a broader business and personal development approach

Encourage life-long learning

Evaluate and improve collaborative selling across channels

Possibility to have a decentralized training session (by the web, for example) or centralized session Consider scientifically-based methods of selection; demand greater rigour, documentation, and justification when using selection tools such as tests

Develop policies that retain good performers and avoid negative turnover 
required so that new knowledge can be leveraged more quickly and effectively. Thus, while sales managers may believe that they have fully leveraged existing technology; one implication is that technology can be used to accomplish these objectives more completely. For example, SFA solutions do not appear to be used effectively to share information beyond the salesperson's immediate supervisor.

Knowledge management, it appears, is becoming critical. Building technological systems for managing multi-channel go-to-market systems is one aspect, but knowledge management has to also consider how to capture both explicit and tacit knowledge of salespeople in order to facilitate access, analysis, and reuse of that knowledge. As technology can be used to create communities of practice, such activities associated with emergent strategy can become more effective.

Many of the managerial implications will be the function of additional research. These executives have raised a number of questions that lead toward interesting and useful study, a few of which will be discussed in the next section.

\section{Future research}

The importance of sales strategies, sales leadership, and technology is very much supported by this work. In many ways, this qualitative research also supports the joint agenda of Ingram et al. (2002), though not, perhaps, in the manner they might have anticipated. This research suggests that the role of the salesperson cannot be considered in isolation, but rather requires the investigator to consider and to explain the role within a complex network of channels with which the customer interacts. One potentially valuable line of future sales research should be, in addition to the more traditional focus on the salesperson, the macro-marketing perspective of the multi-channel organization.

Conflicting trends such as centralization of buying versus centralizing of sales control require examination. Centralizing buying seems to increase the importance of salespeople while increasing control over salespeople through technology can decrease their importance. For example, these executives suggest that the benefits of research into technology adoption have probably been realized. Thus, what is needed is an understanding of how technology contributes to salesperson productivity, whether technology enables greater salesperson creativity or greater control over the salesperson, and other issues that are specific to the nature of the sales function.

Conversely, there are also micro-level issues that need reexamination. One issue that has seen very limited recent research is the nature of selection of the sales force. These executives are concerned with understanding what the future will require of salespeople, and thereby what qualifies someone to be an effective salesperson of the future. Increased job specialization by fragmenting the customer-facing function (for example, the call center prospects, the field rep closes, and other call center services) yields different sets of job requirements than we have traditionally studied. In fact, we have abandoned such research in recent years in favor of more strategic research. The evidence suggests the need to revisit traditional sales management functions such as selection and development of the sales force. The findings suggest that there is a need for both macro- and micro-level research in sales.
There are, of course, any number of countries that could be studied, just as any other set of industries and companies may have generated different perspectives. That is the risk with qualitative research and small, purposive samples (Lincoln and Guba, 1985). This research is not intended to study country differences per se, but does offer insight into the nature of development of the profession.

Qualitative research is limited, obviously, by the nature of the method of inquiry (Strauss and Corbin, 1990). More importantly, the research is limited by one of the very action items for which we call - that of understanding generalizability in terms of strategy. We, as a discipline, present findings on the basis of country or industry, rather than strategy. It is clear, however, from these executives that strategic choices and strategic theories drive their perspective of what is important to understand in the field (cf. Fontana and Frey, 1998), not in each country or industry. These same strategic foundations should drive academia's perspective of what is important as well.

\section{Summary}

The state of the sales profession is in flux. As the results of this study suggest, sales executives are struggling to define the role of the salesperson of the future. Key challenges for executives include adding value to both customer and company, managing the conflict between control for standardization versus freedom for innovation, and selecting salespeople who can adjust to the changing future.

\section{References}

Barth, I. and Biardeau, S. (2002), Les Représentations des

Métiers de la Vente chez les Etudiants, Confrontation d'une Revue de la Littérature et d'une Etude Exploratoire, Congrès Association Française de Marketing, Lille, pp. 345-78.

Bergadaà, M. and Julien, B. (1993), "Une analyse prospective de la fonction vente", Decisions Marketing, Vol. 61 No. 70, pp. 61-70.

Bernthal, M.J., Crockett, D. and Rose, R.L. (2005), "Credit cards as lifestyle facilitators", Fournal of Consumer Research, Vol. 32 No. 1, pp. 130-45.

Carbone, J. (2005), "Reverse auctions become more strategic for buyers", Purchasing, Vol. 134 No. 20, pp. 42-3.

Craig, C.S. and Douglas, S. (2000), International Marketing Research, Wiley, New York, NY.

Darmon, R.Y. (1997), "La vente: quelques grandes tendances actuelles”, Revue Française du Marketing, Vol. 164 No. 4, pp. 121-8.

Deeter-Schmelz, D., Kennedy, K.N. and Goebel, D.J. (2002), "Understanding sales manager effectiveness: linking attributes to sales force values", Industrial Marketing Management, Vol. 31, pp. 617-31.

Fontana, A. and Frey, J.H. (1998), "Interviewing: the art of science", in Denzin, N.K. and Lincoln, Y.S. (Eds), Collecting and Interpreting Qualitative Materials, Sage, Thousand Oaks, CA, pp. 47-78.

Gengler, C.E. and Reynolds, T.J. (1995), "Consumer understanding and advertising strategy: analysis and strategic translation of laddering data", Fournal of Advertising Research, Vol. 35, July/August, pp. 19-33.

Goulding, C. (2005), “Grounded theory, ethnography, and phenomenology: a comparative analysis of three qualitative 
strategies for marketing research", European fournal of Marketing, Vol. 39 Nos 3/4, pp. 294-308.

Honeycutt, E., Ford, J. and Simintiras, A. (2003), Sales Management: A Global Perspective, Routledge, London.

Ingene, C.A. and Parry, M.E. (1995), "Channel coordination when retailers compete", Marketing Science, Vol. 14 No. 4, pp. 360-77.

Ingram, T.N. (2004), "Future themes in sales and sales

management: complexity, collaboration, and accountability", Fournal of Marketing Theory and Practice, Vol. 12 No. 4, pp. 18-28.

Ingram, T.N., LaForge, R.W. and Leigh, T.W. (2002), "Selling in the new millennium: a joint agenda", Industrial Marketing Management, Vol. 31 No. 7, pp. 559-68.

Ji, L.J., Zhang, Z. and Nisbett, R.E. (2004), "Is it culture or is it language? Examination of language effects in crosscultural research on categorization", Fournal of Personality and Social Psychology, Vol. 87 No. 1, pp. 57-65.

Kambil, A. and Van Heck, E. (2002), Making Markets, Harvard Business School Press, Boston, MA.

Kelly, P. (1988), Situational Selling, AMACOM, New York, NY.

Leigh, T.W. and Marshall, G.W. (2001), "Research priorities in sales strategy and performance", fournal of Personal Selling and Sales Management, Vol. 21 No. 2, pp. 83-94.

Lincoln, Y.S. and Guba, E.G. (1985), Naturalistic Inquiry, Sage, Newbury Park, CA.

Marshall, G.W. and Michaels, R.E. (2001), "Research in selling and sales management in the next millennium: an agenda from the faculty consortium", fournal of Personal Selling and Sales Management, Vol. 21 No. 1, pp. 15-18.

Mintzberg, H. (1994), The Rise and Fall of Strategic Planning: Reconceiving Roles for Planning, Plans, and Planners, The Free Press, New York, NY.

Moorman, C. and Miner, A.S. (1998), "The convergence of planning and execution: improvisation in new product development", fournal of Marketing, Vol. 62 No. 3, pp. 1-20.

O'Sullivan, L.F., Heino, F.L., Meyer-Bahlburg, H.F.L. and Watkins, B.X. (2000), "Social cognitions associated with pubertal development in a sample of urban, low-income, African-American and Latina girls and mothers", fournal of Adolescent Health, Vol. 27, pp. 227-35.

Payne, A. and Frow, P. (2004), "The role of multichannel integration in customer management", Industrial Marketing Management, Vol. 33, pp. 527-38.

Rackham, N. (1988), SPIN Selling, McGraw-Hill, New York, NY.

Rapert, M.I., Garretson, J., Velligquette, A., Olson, J. and Dhodapkar, S. (1998), "Domains of quality-based strategies: a functional perspective", fournal of Professional Services Marketing, Vol. 17 No. 2, pp. 69-82.

Reynolds, N.L., Simintiras, A.C. and Diamantopoulos, A. (2003), "Theoretical justification of sampling choices in international marketing research: key issues and guidelines for researchers", fournal of International Business Studies, Vol. 34 No. 1, pp. 80-9.

Robertson, B., Dixon, A.I. and Curry, D. (2006), “An agenda for selling and sales management research: using the financial industry's forward-thinkers for insight", fournal of Personal Selling and Sales Management, Vol. 26, Summer, pp. 293-303.

Sashittal, H.C. and Jassawalla, A.R. (2001), "Marketing implementation in smaller organizations: definition, framework, and propositional inventory", fournal of the Academy of Marketing Science, Vol. 29 No. 1, pp. 50-69.

Schill, R.L. and McArthur, D.N. (1992), "Redefining the strategic competitive unit: towards a new global marketing paradigm?”, International Marketing Review, Vol. 9 No. 3, pp. 5-24.

Shapiro, B.P., Slywotsky, A.J. and Doyle, S.X. (1994), Strategic Sales Management: A Boardroom Issue, Harvard Business School, Boston, MA.

Strauss, A. and Corbin, J. (1990), Basics of Qualitative Research: Grounded Theory Procedures and Techniques, Sage, Newbury Park, CA.

Tang, F.F. and Xiaolin, X. (2001), "Will the growth of multichannel retailing diminish the pricing efficiency of the web?", fournal of Retailing, Vol. 77, pp. 319-33.

Trocchia, P.J. (2004), "Caving, role playing, and staying home: shopper coping strategies in a negotiated pricing environment", Psychology and Marketing, Vol. 21 No. 10, pp. 823-53.

Wotruba, T.R. (1991), "The evolution of personal selling", Fournal of Personal Selling and Sales Management, Vol. 11 No. 3, pp. 1-12.

\section{Corresponding author}

John F. Tanner Jr can be contacted at: jeff_tanner@baylor.edu

\section{Executive summary and implications for managers and executives}

This summary has been provided to allow managers and executives a rapid appreciation of the content of the article. Those with a particular interest in the topic covered may then read the article in tototo take advantage of the more comprehensive description of the research undertaken and its results to get the full benefit of the material present.

When a potential customer for a new automobile was discussing with a salesperson the bewildering array of model choices, specifications and optional extras for a vehicle just launched, he said he would probably choose the diesel automatic. "I'm sorry but I don't think we do an automatic with a diesel engine in this model", said the salesperson. "I think you'll find that you do" said the well-informed customer.

Whereas there was once a time when a customer would have had to rely entirely on a salesperson's knowledge for information about a product or service, or perhaps get some facts and figures from catalogs or magazines, these days information technology has changed things dramatically. The anecdote about the automobile clearly demonstrates two aspects of overwhelming developments which have enveloped the salespersons' role.

Firstly, the need to have considerably more knowledge about the company's products and services than they used to. While a financial services salesperson might tell you: " 15 years ago, we had 30 products to sell; now we have 250 ", so the car salesperson could point to a multiplication of models and specifications and an ever-increasing roll-out of new products. The second point is that a customer, more focused on his or her requirements and perhaps with more time to do it, can go direct to retailers', manufacturers' or service providers' websites to gain the information they need. 
So will salespersons become an extinct species? The pessimists among them might say "yes", but the optimistic - and surely realistic - proposition is that they will evolve into more integrated, knowledgeable value creators for the company, taking on additional responsibility back up the supply chain.

Those who say that face-to-face selling will always be with us (which is probably true) and that the huge diversification in products and services means a salesperson is even more necessary (which is probably also true), should not, however, convince themselves that they will be immune from the need to change.

Buyers will demand more from the product while sellers must add value to the selling process. Margins are declining, and for companies to be able to afford salespeople, salespeople must create value to clients and to companies alike. The issue is not one of simply efficiency; i.e. selling more with the same resource. It is how to justify premium prices that reflect the cost of a professional sales force.

Tanner et al., - who spoke to sales executives in France, the United States and Mexico to determine their views on the changes in nature which the job has witnessed, say: "Sales executives are struggling to define the role of the salesperson of the future. Key challenges for executives include adding value to both customer and company, managing the conflict between control for standardization versus freedom for innovation, and selecting salespeople who can adjust to the changing future."

Managers must prepare their sales force to develop agility capabilities in order to respond well to change. More complex product offerings require methods, perhaps using technology, to manage the complexity of knowledge required to sell a wide range.

Career professionalism demands managers put more emphasis on general business knowledge in training and development so a culture is developed to give salespeople a broader view of their work. Multi-channel tracking technology is required and a system of motivation and compensation must be built which considers all the actors of the channel. Opportunities to sell overseas require the creation of a culture oriented towards others countries and consumers.

The expectation that strategy will become more of an emergent strategy, led by salespeople or sales management, raises the importance of knowledge management and performance tracking throughout sales processes. Information systems should reinforce emergent strategy, integrating CRM systems.

Managers should react to the impact of IT by re-examining sales technology to integrate with existing systems and procedures, by creating knowledge management systems and algorithms, and by determining and developing appropriate levels of access to information. The degree to which customers will manage the relationship through selfservice must be determined and appropriate mechanisms developed for human intervention at the right cost.

In the selection of salespeople, they must become more "business people" leading to training in non-selling areas. One reason for greater business knowledge and ability is so that salespeople can deliver greater value; another is so that they can more effectively engage in emergent strategy.

Assessment of sales skills and knowledge gaps must reflect a broader business and personal development approach, and lifelong learning should be encouraged. Managers should evaluate and improve collaborative selling across channels.

Scientifically-based methods of selection should be considered, with a demand for greater rigor, documentation, and justification when using selection tools such as tests. Policies that retain good performers and avoid negative turnover should be developed.

( $A$ précis of the article 'Executives' perspectives of the changing role of the sales profession: views from France, the United States, and Mexico". Supplied by Marketing Consultants for Emerald.) 